\title{
Imigrantes nos territórios: problematizações sobre intervenções profissionais nas políticas de seguridade social $^{1}$
}

\author{
Líria Maria Bettiol Lanza ${ }^{1,2}$ \\ http://orcid.org/0000-0003-4583-3762
}

Evelyn Secco Faquin ${ }^{1}$

http://orcid.org/0000-0003-3322-8741

\author{
Paula Basilio Alves Ribeiro ${ }^{2}$ \\ http://orcid.org/0000-0002-1488-9088
}

\begin{abstract}
${ }^{1}$ Universidade Estadual de Londrina, Centro de Estudos Sociais Aplicados, Departamento de Serviço Social, Londrina, PR, Brasil (UEL) ${ }^{2}$ Universidade Estadual de Londrina, Departamento de Serviço Social, Programa de Pós-Graduação em Serviço Social e Política Social, Londrina, PR, Brasil (UEL)
\end{abstract}

\begin{abstract}
Imigrantes nos territórios: problematizações sobre intervenções profissionais nas políticas de seguridade social

Resumo: O presente artigo tematiza as configurações contemporâneas dos fluxos migratórios internacionais em cenário brasileiro, com ênfase para o estado do Paraná e suas refrações nas políticas sociais, objetivando problematizar as intervenções profissionais junto aos imigrantes, no interior das políticas de seguridade social. Resulta de dados parciais de projeto de pesquisa em curso, contando com a análise de sessenta formulários dirigidos a imigrantes e nove entrevistas com trabalhadores sociais. Os dados têm origem em cinco municípios com maior incidência de imigrantes em uma região metropolitana, no estado do Paraná/Brasil. A análise demonstra incompreensão acerca dos princípios universalidade e equidade na condução das intervenções, ausência de conhecimento aprofundado sobre as configurações territoriais em que se desenvolvem as prestações e de particularidades dos imigrantes, indicando que seu acesso está em construção e necessita não apenas de investimento do Estado, mas também de um compromisso profissional que compreenda os imigrantes como sujeitos singulares.
\end{abstract}

Palavras-chave: Fluxos Migratórios Internacionais. Território. Seguridade Social. Intervenções Profissionais.

Immigrants in Territories: problematizations about professional intervention in social security policies Abstract: This article considers the contemporary configurations of international migratory flows in the Brazilian situation, with an emphasis on the state of Paraná and its refractions in social policies. The objective is to problematize professional interventions with immigrants in relation to social security policies. The study is based on partial data from a research project underway, and includes an analysis of sixty questionnaires issued to immigrants and nine interviews with social workers. The data originated in five municipalities with the highest incidence of immigrants in a metropolitan region in Paraná state, Brazil. The analysis demonstrates a lack of understanding among social workers about the principles of universality and equity in conducting interventions. It also found an absence of in depth knowledge about the territorial configurations in which the services to and particularities of immigrants develop. This indicates that access to social services among migrants is still under construction and requires not only investments by the state, but also a professional commitment that understands them as unique subjects.

Keywords: International migratory flows. Territory. Social security. Professional interventions.

Recebido em 15.10.2017. Aprovado em 08.02.2018. Revisado em 09.03.2018.

(C) O(s) Autor(es). 2018 Acesso Aberto Esta obra está licenciada sob os termos da Licença Creative Commons Atribuição-NãoComercial 4.0 Internacional (https://creativecommons.org/licenses/by-nc/4.0/deed.pt_BR), que permite copiar, distribuir e reproduzir em qualquer meio, bem como adaptar, transformar e criar a partir deste material, desde que para fins não comerciais e que você forneça o devido crédito aos autores e a fonte, insira um link para a Licença Creative Commons e indique se mudanças foram feitas. 


\section{Introdução}

As imigrações, sobretudo neste século, têm sido alvo de crescentes estudos que têm contribuído para reflexões interdisciplinares diversas. A contribuição do artigo se insere no campo da política social, tendo como objetivo problematizar as intervenções profissionais junto aos imigrantes, no interior das políticas de seguridade social. A região estudada tem, em sua formação socioespacial, a presença de imigrantes orientada pelo País, no início do século XX. Atualmente, o sentido Sul-Sul expressa profundas alterações em termos de (i) raça e etnia, com a predominância de negros, (ii) de posição econômica em âmbito mundial, pois são imigrantes de países tidos como periféricos que têm como marca o transnacionalismo.

A partir de cinco municípios selecionados, com maior incidência de imigrantes, em uma região metropolitana no estado do Paraná/Brasil, este artigo apresenta dados parciais de projeto de pesquisa em curso, referentes à aplicação de sessenta formulários, para caracterizar tais fluxos, bem como entrevistas com nove trabalhadores sociais nas políticas de Previdência Social, Saúde e Assistência Social.

As discussões foram estruturadas em quatro seções. Na primeira, objetivamos apresentar os marcos teórico-metodológicos que sustentaram as reflexões aqui apresentadas, em que a divisão internacional do trabalho e a desigualdade socioespacial reconstroem os fluxos e lhes dão outros sentidos políticos, econômicos e sociais. A segunda seção traz uma caracterização dos atuais fluxos migratórios, dialogando com as vertentes analíticas do transnacionalismo e do sentido Sul-Sul, demarcando a força dos territórios na temática da imigração. Essas reflexões prosseguem nas outras duas seções, sendo uma dedicada ao eixo das políticas públicas e à perspectiva territorial e outra, a última, à presença dos imigrantes nos territórios a partir das intervenções profissionais.

\section{As imigrações no tempo presente}

A mobilidade humana é fato recorrente nas sociedades. Todavia, é no contexto do capitalismo que é dotada de características particulares. Na ordem mundial, a serviço do capital, esse movimento, que pôde, em algum momento dentro da longa história, atender às necessidades humanas, passa a ser controlado e orientado pelas necessidades capitalistas. Apropriada no âmbito científico, é desnecessário aprofundar a relação de dominação e subordinação entre os países tidos como do centro, majoritariamente localizados na Europa e América do Norte, e os outros, como periferia. Nesse sentido, há uma orientação dos atuais fluxos migratórios no sentido Sul-Sul, ou seja, dos periféricos na periferia, bem problematizado por Villen (2015), e que são comuns à realidade estudada. Dessa forma, as análises sobre imigração partem tanto da desigualdade socioespacial quanto dos interesses imediatos e conjunturais das economias desenvolvidas, já que, em primeira instância, elas ocorrem pela necessidade de trabalho.

Dentro dos estudos migratórios, há várias possibilidades de interpretação à luz de diferentes perspectivas teóricas, conforme apontam Rua (1997) e Dutra (2013). A partir das construções teóricas marxistas sobre o capitalismo em que, dada a divisão da sociedade em classes, aos que não detém os meios de produção resta somente a força de trabalho. Dessa forma, o trabalho na sociedade capitalista deve ser analisado como uma chave para perpetuação do sistema pela extração do lucro, mas também pelo seu sentido no processo de sociabilidade humana. Esta última é capitaneada pelo capitalismo e reificada em relações desumanas, alienadas e alienantes, que não se restringem ao mundo do trabalho, mas se espraiam por toda vida social.

Posto isso, compreendemos que justificativas individuais para a decisão de migrar não podem ser descoladas dessa compreensão ampliada dos sentidos do trabalho (ANTUNES, 1999) e mais: que, no caso dos imigrantes, além de servirem, como mão de obra abundante e disponível, às necessidades econômicas do capital, a sua condição de ser um estranho, um outro, torna-os expostos a toda ordem de exploração e desproteção social. O que não significa que as expressões dessa sociabilidade orientada pelo capital não mereçam ser analisadas, no entanto, reitera-se, não devem tomar o lugar de seus determinantes.

Quando problematizado o histórico da imigração em território brasileiro, entendemos que os interesses econômicos e políticos - de produção agrária e de branqueamento da nação - reservaram a determinados grupos - europeus, brancos e cristãos - a possibilidade de entrada no País ${ }^{2}$. O mesmo se refere às atuais políticas restritivas às imigrações dos países centrais, no momento em que vivemos os efeitos de mais uma crise capitalista, que se iniciou nos Estados Unidos em 2008 e espalhou-se de forma mundial.

A partir disso, podemos indicar que as rotas migratórias não podem ser justificadas somente pela relação econômica entre os países, em termos de acordos bilaterais ou similares, mas, sobretudo, pela disponibilidade econômica, pelas facilidades legais e de redes pessoais que dão suporte e acolhimento aos recém-chegados, sempre presentes nas trajetórias desses sujeitos na busca pelo trabalho. 
Dentro das análises sobre os atuais fluxos imigratórios, diante da realidade mundial em tempos de crise, a perspectiva do transnacionalismo, já problematizada por diversos autores (BAENINGER, 2017; PORTES, 2004), possibilita análises considerando tais clivagens acima demonstradas. A noção de provisoriedade, de passagem, caracteriza esses fluxos, tendo em vista que a instalação de imigrantes em um país não significa necessariamente uma longa permanência. As imigrações estabelecem relações econômicas, políticas e culturais entre múltiplos países. Mediante a objetividade de migrar, as rotas só podem ser analisadas considerando a conjuntura mundial dos países e dos territórios marcados pela presença dos imigrantes, conforme problematizaremos na próxima seção.

\section{O Estado do Paraná e o os fluxos migratórios internacionais: aproximações introdutórias}

O Brasil tem experimentado, nos últimos anos, um aumento expressivo do número de imigrantes que chegam ao país. É o que apontam os dados do Instituto Brasileiro de Geografia e Estatística (IBGE) ${ }^{3}$ referentes ao último levantamento censitário. O Paraná recebeu, em 2014, segundo o Ministério da Justiça, cerca de 5 mil imigrantes haitianos, dentro dos 14,5 mil que chegaram ao Brasil juntamente com outras nacionalidades do sentido Sul-Sul (PARANÁ, 2014).

De acordo com estudos de Bettiol Lanza, Santos e Rodrigues (2016), evidenciou-se que a região paranaense está na rota da imigração devido à oferta de empregos formais, estando em $6^{\circ}$ lugar em números absolutos de empregos com carteira assinada (RAMBALDUCCI; KURANAGA; FELTRIN, 2017). Um exemplo é a presença de frigoríficos para abate de frango, área na qual o Paraná divide com Santa Catarina o título de maior produtor do País. Nesse caso, o estado se torna um atrativo para os imigrantes porque os trabalhadores locais tendem a não assumir tais vagas, tendo em vista as condições de trabalho desgastantes e adoecedoras.

Na realidade investigada, $80 \%$ são homens e $20 \%$ são mulheres; em sua maioria migraram sozinhos (65\%) ou acompanhados de familiares (18\%) e amigos (17\%). Em relação à idade, 56\% possuem de 19 a 29 anos e $44 \%$ de 30 a 60 anos. No que tange ao tempo de permanência no Brasil, constatamos que a maioria dos imigrantes se encontra há pouco tempo no País: $25 \%$ de 2 a 3 anos e $24 \%$ de 1 a 2 anos. Apenas $7 \%$ dos entrevistados encontram-se no Brasil há mais de três anos, demonstrando, assim, que as migrações para o nosso País continuam a acontecer, mesmo mediante a crise política e econômica atual do Brasil. Com referência às nacionalidades dos sujeitos, foram identificadas oito: Angola, Bangladesh, Colômbia, Guiné Bissau, Haiti, Nigéria, Senegal e Síria. Três desses países fornecem o maior número de entrevistados até o momento: 47\% são imigrantes haitianos, $14 \%$ do Senegal e $12 \%$ de Bangladesh.

Sobre as razões de imigração, dos 60 entrevistados, $42 \%$ apontaram que a principal causa da emigração estava relacionada ao trabalho, sendo que $57 \%$ estão empregados e destes $65 \%$ possuem registro em carteira de trabalho. Os imigrantes sem acesso ao trabalho são $30 \%$ e demonstram garantir sua subsistência por intermédio de redes de apoio que eles próprios constituem, como familiares, amigos e entidades religiosas. Nas suas residências, demonstraram se comunicar mais em seus idiomas nativos $(70 \%)$ que em português $(23 \%)$ ou utilizarem idiomas de matriz lusófona. Quanto à participação em atividades coletivas com outros imigrantes, $53 \%$ afirmam participar e também manter relações familiares, econômicas e afetivas com outros países.

Analisando os dados apresentados, notamos que os atuais fluxos migratórios são bastante heterogêneos e ocorrem principalmente no sentido Sul-Sul, com característica de transnacionalismo, sobretudo em sua dimensão cultural. As redes de apoio ajudam a ressignificar o território no qual atualmente se encontram inseridos, trazendo elementos como: o uso permanente dos idiomas nativos e o contato com outros imigrantes. Em termos econômicos, identificamos somente o envio de remessas em dinheiro aos países onde mantêm relações familiares. Diante dessa configuração, são homens e mulheres que usam o território, dando-lhe sentido e particularidade. Na próxima seção, será discutido como a perspectiva territorial no desenvolvimento das políticas sociais poderia contribuir para o acesso dos imigrantes às essas políticas.

\section{Políticas públicas e a perspectiva territorial}

A promulgação da Constituição Federal de 1988, marco legal e institucional do País, estabelece, como ordenamentos importantes, princípios para as políticas sociais no Brasil, dentre eles a universalidade; a descentralização político-administrativa; a participação popular com vista ao controle social e a gestão democrática das políticas sociais. O processo de descentralização político-administrativa impulsiona a inclusão dos municípios como principais executores das políticas sociais. Assim, os municípios se tornam a maior aproximação territorial, referência para organização e definição de prioridades para as políticas públicas. Ressaltamos que esse processo teve limites quanto 
ao seu alcance, mediante restrita partilha de responsabilidades, poder e recursos financeiros.

Todavia, os territórios locais, nos quais se inserem os municípios, aparecem como pontos estratégicos para organizar o acesso da população aos serviços e bens públicos, suscitando a necessidade de uma leitura territorial, que permita não só o reconhecimento das demandas sociais, mas que também possibilite entender o território a partir do seu uso, e não apenas como um território político-administrativo definido por aparato jurídico.

Por território, nos valemos dos estudos de Santos (2005) quando este explana que deve sempre ser considerado a partir do seu uso, pois se compõe como espaço concreto e produto da história e da transformação humana. Logo, o que deve ser objeto de análise não é o território em si mesmo ou as delimitações espaciais definidas pelo Estado e pelas políticas sociais, mas sim a forma como ele é utilizado e transformado pelos que o usam, sendo ele aglutinador da história, da identidade, das relações de poder e da organização de uma determinada população.

Dessa maneira, para os sujeitos hegemônicos, o território usado se coloca como um recurso conforme é utilizado como garantia de interesses particulares e exógenos ao território, relacionado a seu uso corporativo que "aprofunda a divisão social e territorial do trabalho, mediante a seletividade dos investimentos econômicos". (SANTOS et al., 2000, p. 108). Para os sujeitos hegemonizados, o território se coloca como abrigo, pois esses atores se utilizam do território criando e recriando estratégias que garantam sua sobrevivência nos lugares e se adaptando ao meio local. O território usado, visto como uma totalidade, conforme apontam Santos et al. (2000), se mostra um campo privilegiado para a análise do acesso às políticas sociais, pois revela a estrutura e organização global da sociedade capitalista, mas também é capaz de mostrar as particularidades do seu uso.

A Seguridade Social no Brasil, disposta pelo artigo número 194 da Constituição Federal de 1988, estabeleceu a previdência social, a saúde e a assistência social como constituintes desse sistema. Estruturadas e articuladas por meio do princípio da descentralização político-administrativa, expressam a organização territorial em seus marcos legais, no que tange às ofertas de seus serviços.

A saúde se coloca como direito universal e dever do Estado em todos os níveis de governo. A partir de uma concepção ampliada, prevê ações para sua promoção, proteção e recuperação, organizando, através de um sistema único, a oferta de serviços e ações sem a necessidade de contribuição prévia por partes dos usuários (BRASIL, 1988). Para a política de saúde, conforme apontado por Gondim e Monken (2008), a utilização do território ocorre por meio de horizontalidades, o que visa ultrapassar as hierarquizações territoriais, com vista à organização das redes de atendimento ofertadas pelo Estado, considerando que a perspectiva de territorialização faça parte dos processos formativos em saúde e destacando o papel dos profissionais nesse contexto.

No caso da assistência social, política social de caráter não contributivo e ofertada "a quem dela necessitar", os documentos normativos expressam a abordagem territorial a partir do ano de 2004, quando é instituída a Política Nacional de Assistência Social (PNAS) (BRASIL, 2004), colocando a territorialização como um dos eixos estruturantes do Sistema Único de Assistência Social (SUAS). A lógica territorial adotada pela assistência social orienta a superação da fragmentação das ações, a vigilância social das vulnerabilidades sociais, indicando a organização de programas, projetos e serviços a partir da proximidade com o cidadão.

Tratando-se da Previdência Social, que se estrutura na lógica do seguro social para trabalhadores inseridos no mercado formal de trabalho, destacamos sua organização do ponto de vista da descentralização político-administrativa de acordo com os marcos regulatórios. No aspecto de territorialização, embora existam as sedes físicas nos municípios, não é possível afirmar que exista uma perspectiva de leitura territorial que considere o território a partir do seu uso, mas sim que se oriente pelos recortes estatais dos espaços, sendo dotada de um caráter verticalizado e centralizador nas ações, pois conservou aspectos restritivos de sua história e desenvolvimento.

A apropriação do território pela seguridade social permitiu que, mesmo de forma burocratizada e institucionalizada, esses territórios fossem conhecidos pelas políticas sociais, embora desconhecidos pelos imigrantes. Logo, esse novo uso territorial deveria ser identificado, compreendido e apreendido, indicando a permanente necessidade de novas leituras espaciais.

Cabe problematizar, então, a pouca habilidade e conhecimento demonstrados por parte dos serviços sobre a presença dos imigrantes nos territórios que estão instalados. Nessa direção, indicamos a leitura territorial enquanto instrumento, que pode vir a contribuir para o alargamento das possibilidades de intervenção e qualificação das respostas a serem construídas pelas políticas às demandas postas, sobretudo pelos imigrantes.

Ter a leitura territorial como instrumento, requer entendê-la como um conjunto de procedimentos materiais e não materiais, resultantes da própria compreensão dos ordenamentos das políticas. Ela é detentora de potencial porque possibilita a dimensão do novo diante das particularidades dos territórios nos quais se encontram os serviços. Também, possibilita o planejamento de intervenções que dialogam diretamente com as necessidades postas por estes territórios.

Havendo um direcionamento territorial nas políticas de seguridade social, o instrumento não exige esforços para além das orientações em vigência. No entanto, a pesquisa em curso indicou ausência de bases sólidas acerca 
desse instrumento, quando dialogamos sobre os atendimentos prestados ao público imigrante. O uso da leitura territorial seria recurso para evitar orientações centralizadas/centralizadoras distantes de suas realidades, dando visibilidade às expressões dos fluxos migratórios in loco, ou seja, como os territórios se reorganizam a partir destes e que intervenções são necessárias para o atendimento às demandas e alargamento do acesso.

A leitura territorial é também potente como instrumento compilador de dados e na sua sistematização por consequência, para orientar as ações públicas. No que tange aos fluxos migratórios internacionais, a pesquisa demonstrou a inexistência de construções nesse sentido, havendo somente informações repassadas de modo oral, sem sistematização e análise, tornando urgente a criação de rotinas de registro de dados e produção de informações na direção da retroalimentação dos processos de trabalho, contemplando as ofertas de serviços presentes nos territórios.

\section{Intervenções profissionais e o acesso de imigrantes às políticas de seguridade social}

Ao problematizarmos o acesso dos imigrantes às políticas de seguridade social a partir das intervenções profissionais, é preciso situar essas práticas como expressão do trabalho desenvolvido por esses sujeitos. Partindo do referencial marxista acerca da categoria, tanto em seu conteúdo emancipatório quanto em sua ressignificação no capitalismo, é conhecida e afirmada a centralidade do trabalho no processo de sociabilidade, assim como as constantes investidas do capital ao trabalho corporificadas nas múltiplas transformações vivenciadas ao longo das décadas (ANTUNES, 2005; HARVEY, 2011).

A análise da categoria trabalho nos orienta à compreensão de que a esta se associa necessariamente a concepção de transformação. Transformação forjada a partir de um processo composto por objeto (sob o que se desenvolve o trabalho, que se altera e adquire novas expressões à medida que se estabelecem mudanças macrossocietárias), meios/instrumentos (mecanismos utilizados para sua efetivação, sendo materiais e imateriais, incluindo o trabalho intelectual) e produto (resultado do trabalho em si).

No entanto, o processo de transformação operacionalizado pelo trabalho se vincula estreitamente à intencionalidade que o desencadeou. Nessa direção, os trabalhadores, especialmente no setor de serviços, têm relação intrínseca com este processo, pois a eles compete, se não a definição do objeto sobre o qual incidirá o trabalho, ao menos as estratégias/meios a serem empreendidos em sua efetivação. Assim, processo de trabalho se define como produção de conjunto de ações vinculadas a um fim, definido primordialmente pela capacidade teleológica dos trabalhadores que o executam.

No tempo histórico em que Marx escreve e tematiza as classes sociais a partir da prevalência do setor industrial, o setor de serviços é considerado residual, restrito e de pouca expressão política e econômica, uma vez que sua produção capitalista é muito limitada (MARX, 1969). Todavia, no contexto da mundialização e de profundas transformações no mundo do trabalho, o setor de serviços emerge como uma necessidade para pensar o trabalho desenvolvido nas políticas sociais que se localizam nele.

A divisão sociotécnica do trabalho é ampliada ${ }^{4}$, posto que se assiste a um novo rol de profissões oriundas nesse setor, de tal forma que há uma crescente fragmentação desses trabalhadores, acrescida de uma heterogeneidade, o que o torna campo de análise complexo em termos de caracterização e definição. Todavia, há alguns elementos que expressam uma certa padronização. Para fins desta pesquisa, com alvo no trabalho nas políticas sociais, elencamos três deles: (i) a indissociabilidade entre produção e consumo, tendo em vista a inexistência de um produto externo ao trabalhador; (ii) a capacidade de particularizar e individualizar o trabalho para atender necessidade do consumidor (usuário das políticas sociais) e (iii) permanência em um campo no qual são necessárias mediações constantes, dado o contexto extremamente dinâmico das relações sociais.

Nessa direção, o trabalho desenvolvido no âmbito das políticas sociais envolve aquelas características anteriormente apontadas e auxiliam na problematização das intervenções profissionais junto aos imigrantes no acesso a bens e serviços públicos.

Elencamos como características definidoras do setor de serviços, a ausência de um produto final com materialidade corpórea e o fato de a ação produtiva não se dar por intermédio de objetos, mas sim de pessoas. Nesse sentido, ao refletir sobre esse tipo de produção imaterial, devemos considerar que os meios de produção possuem características particulares, assim como a força de trabalho e a necessidade de participação dos usuários oferecem valores de uso necessários para a realização do trabalho (MERHY, 2008).

Dessa forma, é evidente a existência de aspectos relacionais que caracterizam esse tipo de trabalho e envolvem no mínimo duas pessoas: o usuário e o trabalhador social. Ambos utilizam várias ferramentas para efetivar determinada produção: conhecimentos e instrumentos técnicos estruturados; estratégias de comunicação; informações; valores e normas, dentre outros. Todavia, como expressão do trabalho de forma geral, o setor de serviços apresenta componentes da divisão sociotécnica do trabalho expressas 
pela tensão entre oferta e necessidades humanas. Sendo assim, os trabalhadores sociais detêm maior grau de poder nessa relação, cabendo aos usuários uma participação instrumental no processo de trabalho, contribuindo com as requisições que lhe são feitas, quer sejam informações, documentos ou formas de adesão/condicionalidades.

As reflexões em torno do acesso dos imigrantes aos serviços públicos no âmbito da seguridade social, na realidade estudada, demonstram que a comunicação, dificuldades relacionadas ao domínio do idioma português e ausência de intérpretes nos locais de atendimento constituem as maiores queixas em termos de dificuldades enfrentadas pelos profissionais das três políticas. No entanto, devemos provocar que, em termos de qualidade, o trabalho ofertado apresenta um problema de origem, uma vez que as incompreensões comprometem o processo como um todo.

Ao serem construídos por meio de gestos e deduções, esses encontros realizados nos atendimentos aos imigrantes são destituídos de conteúdo significativo para as duas partes, pois, mesmo que a necessidade imediata tenha sido suprida, perderam-se no caminho os condicionantes que a orientaram e, assim, aos imigrantes cabe a aceitação do que lhes é ofertado e ao mesmo tempo negado: o direito de conhecer as políticas e de reivindicar qualquer melhoria de qualidade, de conteúdo, de humanização, reforçando a perspectiva de subalternidade entendida, em termos gramscianos, como formas de apoliticismo e desagregação (GRAMSCI, 2011).

Do ponto de vista do trabalho, encontramos na pesquisa, em menor número, autocrítica de profissionais que, desafiados por esse contexto, associaram as dificuldades de ampliar o escopo dos atendimentos para além da demanda imediata (de ordem básica nas três políticas) e captarem com clareza os determinantes culturais e sociais que compõem o mosaico das necessidades humanas dos imigrantes. Notamos que os imigrantes não têm sido vistos como público dotado de particularidades, e seu atendimento, portanto, necessita de redimensionamento de gestão em nível municipal e local. É possível, então, inferir a ausência de conhecimento sistematizado acerca dos territórios. Não sendo conhecida pelos profissionais sua estruturação em termos de recorte populacional, nem seus usos, a emergência dos fluxos migratórios é invisibilizada na qualidade de novos sujeitos que usam e produzem os territórios.

Embora não tenhamos conseguido identificar, na gestão municipal, orientações relacionadas ao atendimento das demandas postas pelos imigrantes, devemos ressaltar poucas, mas importantes, estratégias pessoais de alguns profissionais para seu enfrentamento, como a identificação de parceiros, majoritariamente na sociedade civil, sobretudo no âmbito religioso e de cunho voluntário, e a necessidade de ações intersetoriais. Destacamos o silêncio da gestão municipal nesse processo, tornando as iniciativas endógenas a determinado serviço e altamente dependentes do profissional. Nesse sentido, embora valorativas, correm o risco de serem ações isoladas e restritas, com pouca capacidade de reorientar o atendimento aos imigrantes de modo geral.

De forma expressiva, a maioria dos trabalhadores, mediante uma comunicação truncada e limitada, expressou estereótipos, preconceitos e simplificações de questões relacionadas aos modos de vida e de trabalho dos sujeitos, assim como expressões de uma noção de assimilação como forma de superar as dificuldades. Sendo assim, aos que compreendem melhor o idioma, é reservada a valoração de se diluírem na qualidade de sujeitos entre os nacionais. Essa compreensão leva a perdas significativas da alteridade e do alcance das ações, pois, ao igualar diferentes, não se enfrenta de fato questões dorsais para o enfrentamento das problemáticas encontradas, como aquelas relacionadas à xenofobia, ao racismo e ao gênero.

Constatamos, por meio da pesquisa, que a condução dos processos de trabalho tem se dado sob o viés da universalidade, o que não é de longe algo negativo, mas agregamos a essa análise o fato de não estar sendo levada em consideração a equidade (princípio doutrinário do SUS e organizativo do SUAS) nessa prestação. Realizamos essa afirmação a partir da tônica na resposta de todos os entrevistados: afirmarem que os imigrantes são atendidos como qualquer brasileiro, possuindo os mesmos acessos e o mesmo atendimento. Consideramos que esse direcionamento ao invés de ampliar, dificulta o acesso, uma vez que essa 
população, por sua própria condição de imigrante, de não deter as mesmas trajetórias da população brasileira junto aos serviços, se depara com barreiras de origem.

Ou seja, além da questão da linguagem, que dificulta a comunicação, como apresentado pelos profissionais, existe também a ausência de conhecimento acerca do funcionamento do sistema de proteção social brasileiro, dificuldades com a regularização de documentação e culturas distintas. Para essa população, é necessário que seja prestado um atendimento para além de universal: equânime.

Em relação à particularidade e à individualização dos processos de trabalho nos serviços, é evidente que atuam sobre as necessidades de homens e mulheres que se dinamizam cotidianamente frente a novas necessidades humanas e sociais, em demandas por direitos e reconhecimento (JELIN, 2006; FRASER, 2008). É conhecido na produção do conhecimento que a consecução dos processos de trabalho no campo das políticas sociais, dialoga diretamente com a forma como as políticas sociais se estruturam e estabelecem padrões de resultados/efetividade a serem atingidos em cada área e requisitados aos trabalhadores, bem como com os contextos sociopolíticos e ideopolíticos que permitem sua materialidade. Nesse sentido, a ausência de um Estado de Bem-Estar Social consolidado no Brasil, nos termos originários dos países europeus, tidos como modelos, comprometeu uma suposta efetivação desse tipo de Estado, constituindo uma tensão permanente entre os princípios da universalização e da focalização (VIANNA, 2008), com desdobramentos na institucionalização da seguridade social, evidenciando tendências à homogeneização das demandas e suas respostas, que informam uma ação pragmática, tecnicista e controladora.

Para os profissionais que atuam junto aos imigrantes, de acordo com nossa pesquisa, o binômio universalidade e focalização como eixos de análise central se desdobram em três macrotendências no âmbito do trabalho desenvolvido: universalização às avessas no interior das políticas; percepção quantitativa das demandas e focalização no atendimento. Os dados demonstram que a universalização se descola da equidade, conforme problematizado anteriormente, e ocorre uma espécie de individualização dos riscos (FLEURY, 2008), já que o imigrante é responsabilizado por não haver, no interior dos serviços, ações específicas. Os motivos alegados são o uso reduzido de determinadas políticas por imigrantes ou a pequena expressão numérica desse grupo diante do conjunto de usuários total, tendo diminuído substancialmente nos últimos anos, na região estudada, segundo os profissionais.

A presença de barreiras geográficas e informacionais no acesso ${ }^{5}$ aos serviços fica evidenciada quando $62 \%$ dos imigrantes relatam conhecer o Sistema Único de Saúde, $63 \%$ declaram conhecimento acerca da localização de seus serviços e $77 \%$ afirmam já terem sido atendidos por estes, com ênfase para o acesso via Unidade Básica de Saúde (UBS), sendo a política com maior capilaridade junto aos imigrantes.

$\mathrm{Na}$ Assistência Social, foi possível identificar que o acesso é mais restrito, à medida que somente $32 \%$ afirmam conhecer a área, $26 \%$ a localização dos serviços e $27 \%$ terem sido atendidos, principalmente via Centro de Referência da Assistência Social (CRAS), 22\% declaram ter Cadastro Único (o que destoa quando comparamos à renda familiar destes 6 ) sendo que $71 \%$ dos imigrantes relatam não atendimento por ausência de conhecimento acerca da estrutura de assistência social. Em nossa análise, a previdência social já tem um pressuposto dificultador a partir de sua obrigatoriedade de contribuição e isso se expressa na informação sobre ela: apenas $20 \%$ declaram conhecê-la, sendo essa a mesma porcentagem dos que a acessaram.

Um comparativo é possível a partir das entrevistas realizadas com profissionais. A maioria, mesmo tendo atendido imigrantes, relata que estes não requisitam ações diferenciadas e se incluem no conjunto dos demais usuários das políticas, havendo entre eles ausência de informações ${ }^{7}$ sistematizadas. Dessa forma, já encontramos dificuldades engendradas no interior das ferramentas das próprias políticas.

Questiona-se, então, o confinamento espacial das políticas que, contraditoriamente, têm como um dos seus eixos norteadores o território. Nele expressam as necessidades imediatas, visíveis, e as necessidades invisíveis, exigindo uma expansão do seu alcance para além da administração do existente, a saber, a função protetiva na assistência social e a promoção e prevenção, no contexto da concepção ampliada de saúde. Ao lado dessa compreensão, do uso do princípio da universalidade e de confinamento espacial caminha a perspectiva da focalização, em que os programas e benefícios imediatos orientam as ações e atendimentos aos imigrantes que procuram os serviços.

São atendimentos pontuais no sentido de queixa-conduta, restringindo o potencial ampliado a que se propõem as políticas de saúde e assistência social, circunscrevendo o acesso às ações curativistas, medicamentosas e individualistas, no caso da saúde, e focadas nas necessidades básicas de sobrevivência, majoritariamente de alimentos, no caso da assistência social. Tal fato nos remete aos primórdios das políticas no Brasil, não somente em termos de atender aos mais pobres, mas no sentido político em que se construíram no recente século XX.

Dessa forma, o trabalho nas políticas sociais, reconhecido e problematizado como típico do setor de servi ços, pode ser interpretado como uma expressão da ausência de conhecimentos aprofundados de sua própria 
natureza. São faltas de ordem teórica, sobre os processos de trabalho, mas também são faltas políticas, sobre o que propõem as políticas em termos de macro-orientações, especialmente da perspectiva territorial, que, no caso dos imigrantes, tornam-se cruciais para dar-lhes visibilidade como sujeitos sociais e possuidores de direitos.

Por fim, acrescentamos o fato de que foi registrado, em um serviço específico de um dos cinco municípios estudados, preocupação e ações que consideraram os imigrantes e suas necessidades. Em todos os demais, é ausente a voz destes sujeitos. Não há registro de espaços coletivos e de controle social que reserve a esses sujeitos qualquer possibilidade de expressar-se, mesmo com dificuldades, de tal forma que o serviço do município recém mencionado se torna emblemático por atingir ou contemplar suas características estruturais. Ao contrário, são perceptíveis desserviços que produzem isolamento em vez de encontros; no lugar de considerar as particularidades, homogeneízam e restringem as necessidades humanas e sociais ao imediato. Ainda, indicam que, ao contrário da dinamicidade que envolve o trabalho nesse setor, sobretudo em áreas complexas como a das políticas sociais, não há um aprimoramento das formas de trabalho anteriores, da mesma forma como não há reconhecimento de novas necessidades.

\section{Considerações finais}

A partir da problematização proposta por este artigo acerca das intervenções profissionais junto aos imigrantes no âmbito da seguridade social, verificamos que é preciso consolidar a compreensão sobre as concepções de universalidade e de equidade, tendo em vista que ambas são princípios fundamentais, direcionadoras da gestão e da prestação das ofertas dos serviços de seguridade social. A oferta e gestão constroem-se a partir das configurações territoriais e das particularidades dos sujeitos e de suas necessidades, em específico dos imigrantes, indicando a leitura territorial como instrumento para ampliação de análises e sistematização de dados, com vista ao tensionamento da gestão quanto às novas demandas apresentadas e à urgência de desenvolvimento de ações que dialoguem com estas.

Foi possível constatar também que a consolidação dos acessos às políticas de seguridade social tem se expressado de modo diferenciado, com a reposição de algumas barreiras, como a ausência de menção, na estrutura organizacional, à particularidade dos imigrantes e de profissionais com capacitação para prestação no idioma deles. Não há nem mesmo conhecimento acerca da herança cultural dos sujeitos, o que pode gerar compreensões diferenciadas quanto às provisões a serem prestadas por cada área, assim como seus valores e construção social.

Por se constituírem em serviços, identificamos que o caráter dinâmico e inovador, fruto da permanente reconfiguração das relações sociais (matéria-prima em que atua) das intervenções profissionais negligenciam a presença dos imigrantes nos territórios, com diferentes justificativas, seja pela via da invisibilidade ou pela da homogeneização enquanto diagnóstico territorial. Reservam, ainda, a esses sujeitos uma restrita oferta de ações vinculadas aos benefícios, permanecendo aquelas mais afeitas à dimensão protetiva sem referência, ao menos como devir.

Por fim, compreendemos que o acesso dos imigrantes às políticas de seguridade social está em construção e necessita de um robusto investimento do Estado, mas também de um compromisso profissional que compreenda os imigrantes como sujeitos singulares, inseridos nos territórios, com direito a serviços públicos que respeitam suas particularidades.

\section{Referências}

ANTUNES, R. O caracol e sua concha: ensaios sobre a nova morfologia do trabalho. São Paulo: Boitempo, 2005.

. Os sentidos do trabalho: ensaio sobre a afirmação e a negação do trabalho. São Paulo: Boitempo, 1999.

BAENINGER, R. Migrações transnacionais de refúgio no Brasil. In: LUSSI, C. (Org.). Migrações internacionais: abordagens de direitos humanos. Brasília: CSEM - Centro Scalabriniano de Estudos Migratórios, 2017. p. 13-29.

BETTIOL LANZA, L. M.; SANTOS, A. de B.; RODRIGUES, J. R. Imigração, território e as políticas de seguridade social. Argumentum, Vitória, v. 8, n. 3, p. 54-66, set./dez. 2016.

BRASIL. Ministério do Desenvolvimento Social e Combate à Fome. Resolução no 145 do Conselho Nacional de Assistência Social, de 15 de outubro de 2004. Diário Oficial da União, Brasília, DF, 28 out. 2004. Disponível em: <http://pesquisa.in.gov.br/imprensa/jsp/ visualiza/index.jsp?data=28/10/2004\&jornal=1\&pagina=110\&totalArquivos=196>. Acesso em: 01 out. 2017.

. Constituição (1988). Constituição da República Federativa do Brasil. Diário Oficial [da] República Federativa do Brasil, Brasília, DF, 05 out. 1988. Disponível em: <http://www.planalto.gov.br/ccivil_03/constituicao/constituicao.htm>. Acesso em: 01 out. 2017.

DUTRA, D. Migração internacional e trabalho doméstico: mulheres peruanas em Brasília. Brasília: CSEM; Sorocaba: OJM, 2013. 
FLEURY, S. Reforma do Estado, Seguridade Social e Saúde no Brasil. In: MATTA, G. C.; LIMA, J. C. F. (Org.). Estado, sociedade e formação profissional em saúde: contradições e desafios em 20 anos do SUS. Rio de Janeiro: Fiocruz, EPSJV, 2008. p. 49-87.

FRASER, N. Reenmarcar la justicia en un mundo en globalización. In:____. Escalas de justicia. Barcelona: Herder, 2008. p. 31-64. GONDIM, G. M. M.; MONKEN, M. Territorialização em Saúde. In: PEREIRA, I. B.; LIMA, J. C. F. (Orgs.). Dicionário da educação profissional em saúde. 2. ed. Rio de Janeiro: EPSJV, 2008. p. 392-399.

GRAMSCI, A. Caderno 25 (1934): Às margens da história (História dos grupos sociais subalternos). In: Cadernos do cárcere.

2. ed. Rio de Janeiro: Civilização Brasileira. v. 5, p. 129-145, 2011.

HARVEY, D. O enigma do capital: e as crises do capitalismo. São Paulo: Boitempo, 2011.

INSTITUTO BRASILEIRO DE GEOGRAFIA E ESTATÍSTICA. Pesquisa Nacional por Amostra de Domicílios Contínua. 2017. Disponível em: $<$ https://ww2.ibge.gov.br/home/estatistica/indicadores/trabalhoerendimento/pnad_continua $>$. Acesso em: 30 set. 2017. ago. 2017

Censo Demográfico. 2010. Disponível em: <https://ww2.ibge.gov.br/home/estatistica/populacao/censo2010/>. Acesso em: 04

JELIN, E. Cidadania Revisitada: Solidariedade, Responsabilidade e Direitos. In: ;; HERSHEBERG, E. (Org.). Construindo a Democracia: Direitos Humanos, Cidadania e Sociedade na América Latina. São Paulo: EDUSP, 2006. p. 155-179.

MARX, K. Capitulo VI Inédito de O Capital. São Paulo: Moraes, 1969.

MERHY, E. E. Saúde: a cartografia do trabalho vivo. 3 ed. São Paulo: HUCITEC, 2008.

PACHECO, C. A.; PATARRA, N. L. Movimentos migratórios anos 80: novos padrões? In: PATARRA, N. L. et al. (Org.). Migração, condições de vida e dinâmica urbana: São Paulo 1980-1993. Campinas: Unicamp 1997. p. 25-52.

PARANÁ. Secretaria de Estado da Justiça, Cidadania e Direitos Humanos. (Coord.) Plano Estadual de Políticas Públicas para Promoção e Defesa dos Direitos de Refugiados, Migrantes e Apátridas do Paraná/2014 - 2016. Curitiba, 2014. Disponível em:<http:/ /www.dedihc.pr.gov.br/arquivos/File/2015/PlanoEstadualMigranteRefugiadoParana.pdf $\$$. Acesso em: 01 out. 2017.

PORTES, A. Convergências teóricas e dados empíricos no estudo do transnacionalismo imigrante. Revista Crítica de Ciências Sociais, Coimbra, n. 69, p. 73-93, out. 2004.

RAMBALDUCCI, M.; KURANAGA, A. A.; FELTRIN, B. R. Acompanhamento e análise do mercado de trabalho nas principais cidades da região metropolitana de Londrina. Londrina: UTFPR, 2017. Disponível em: <http://www.utfpr.edu.br/londrina/estruturauniversitaria/diretorias/dirppg/pos-graduacao/pesquisa-em-cesta-basica-de-londrina/mercado-de-trabalho-na-rmlo-relatorios-anteriores/ relatorio-referente-a-abril-de-2017>. Acesso em: 17 ago. 2017.

RUA, J. Repensando a geografia da população. Geo UERJ, Rio de Janeiro, n. 1, p. 57-71, jan. 1997.

SANTOS, M. O retorno do território. Observatorio Social de América Latina, Buenos Aires, ano 6, n. 16, p. 251-261, enero/abr. 2005.

. et al. O Papel Ativo da Geografia. Um Manifesto. Revista Território, Rio de Janeiro, ano 5, n. 9, p. 103-109, jul./dez. 2000. TEIXEIRA, F. B.; OLIVEIRA, A. T. R. (Des)informações em saúde: registros sobre adoecimento/cuidado/morte de migrantes no Brasil. In: LUSSI, C. (Org.). Migrações internacionais: abordagens de direitos humanos. Brasília: CSEM - Centro Scalabriniano de Estudos Migratórios, 2017. p. 251-266.

TRAVASSOS, C.; CASTRO, M. S. M. de. Determinantes e Desigualdades Sociais no Acesso e na Utilização de Serviços de Saúde. In: GIOVANELLA, L. et al. (Org.). Politicas e sistemas de saúde no Brasil. Rio de Janeiro: FIOCRUZ, 2008. p. 215-243.

VIANNA, M. L. T. W. A nova política social no Brasil: uma prática acima de qualquer suspeita teórica? Revista Praia Vermelha, Rio de Janeiro, v. 18, n. 1, p. 120-145, 2008.

VILLEN, P. O estigma da ameaça ao emprego pelos periféricos na periferia: crise e imigração no Brasil. RUA, Campinas, v. 21, n. 2, p. 247-264, nov. 2015.

\section{Notas}

1 O presente artigo é resultante do Projeto de Pesquisa em curso “Trajetórias de Imigrantes nos Territórios: a construção do acesso às Políticas de Seguridade Social“" financiado pela Fundação Araucária de Apoio ao Desenvolvimento Científico e Tecnológico do Estado do Paraná, por meio do Programa de Pesquisa Básica e Aplicada da Universidade Estadual de Londrina (Edital PROPPG 03/2016), com período de execução de março de 2017 a março de 2019.

2 Para uma compreensão das migrações no Brasil, consultar Pacheco e Patarra (1997).

3 Os dados do Censo de 2010 apontam que, no Brasil, havia 286.468 imigrantes residindo no país há mais de 5 anos. Um aumento de $86,7 \%$ em relação ao Censo realizado nos anos 2000. Os estados de São Paulo, Paraná e Minas Gerais receberam juntos mais da metade desses imigrantes (INSTITUTO BRASILEIRO DE GEOGRAFIA E ESTATÍSTICA, 2010).

4 Os dados da Pesquisa Nacional por Amostra de Domicílios Contínua (PNAD Contínua) sobre o setor de serviços no Brasil apontaram que, no segundo trimestre de $2016,67,7 \%$ da população ocupada trabalhava no setor terciário, apenas 14,2\% na indústria e 10,4\% na agricultura. Desses, 24, ou seja, $5 \%$ atuam em atividades de interesse público, inclusas o trabalho nas políticas de seguridade social (INSTITUTO BRASILEIRO DE GEOGRAFIA E ESTATÍSTICA, 2017).

5 Refletir acerca dos acessos a essas políticas requer partir dos condicionantes e das estruturas descritas, sendo necessário também debater 
conceitualmente a própria categoria acesso. Diante das imprecisões e multiplicidades de definições, para fins deste trabalho, partiremos da concepção de acesso concebida por Travassos e Castro (2008), enquanto sinônimo de acessibilidade, a partir de suas três dimensões, a saber: disponibilidade dos serviços; capacidade de efetivação de pagamento por parte dos usuários e aceitabilidade, sendo a informação inerente às três dimensões. Podem ter acesso mais amplo ou restrito, sendo estes percursos diferenciados a partir de suas especificidades, expressando a capacidade da oferta em atender às necessidades da população. Agregadas às dimensões elencadas pelas autoras, estão também o que chamam de barreiras, pois compreendem que a disponibilidade por si só não é suficiente para a concretização do acesso em âmbito público. Desse modo, apresentam as seguintes barreiras: geográficas; financeiras; organizacionais; informacionais e culturais.

6 A pesquisa demonstrou que a maior parte dos imigrantes (47\%) tem renda mensal entre $\mathrm{R} \$ 1.001,00$ a $\mathrm{R} \$ 1.500,00$.

7 No que concerne à saúde, Teixeira e Oliveira (2017) chamam a atenção para a ausência de inclusão, nos registros do campo, da nacionalidade/país de nascimento, gerando uma dificuldade de agregar visibilidade à demanda, realidade que se expressa em nossa pesquisa.

\section{Líria Maria Bettiol Lanza}

liriabettiol.j@gmail.com

Doutora em Serviço Social pelo Programa de Estudos Pós-Graduados em Serviço Social da Pontifícia Universidade Católica de São Paulo (PUC-SP)

Docente do Departamento de Serviço Social e Programa de Pós-Graduação em Serviço Social e Política Social da Universidade Estadual de Londrina (UEL)

\section{Evelyn Secco Faquin}

evelynseccofaquin@gmail.com

Doutora em Serviço Social pelo Programa de Estudos Pós-Graduados em Serviço Social da Pontifícia Universidade Católica de São Paulo (PUC-SP)

Professora do Departamento de Serviço Social da Universidade Estadual de Londrina (UEL)

\section{Paula Basilio Alves Ribeiro}

paulabasilioar@gmail.com

Mestranda no Programa de Pós-Graduação em Serviço Social e Política Social da Universidade Estadual de Londrina (UEL)

Bolsista Fundação Araucária no Programa de Pós-Graduação em Serviço Social e Política Social da Universidade Estadual de Londrina (UEL)

\section{UEL}

Rodovia Celso Garcia Cid, s/n - Campus Universitário

Londrina - Paraná - Brasil

CEP: 86.057-970

\section{Agradecimentos}

Agradecemos aos integrantes do Grupo de Pesquisa do CNPq "Serviço Social e Saúde: formação e exercício profissional" pelas contribuições no desenvolvimento da pesquisa.

\section{Agência financiadora}

Fundação Araucária de Apoio ao Desenvolvimento Científico e Tecnológico do Estado do Paraná - Chamada Pública de Programa Institucional de Pesquisa Básica e Aplicada n. 09/2016. O Projeto está cadastrado na Pró-Reitoria de pesquisa e Pós-Graduação (PROPPG/UEL), n. 10630.

Período de vigência: de 04/2017 a 04/2019.

\section{Contribuições dos autores}

$\mathrm{O}$ artigo foi construído coletivamente pelas autoras desde sua fase de elaboração inicial e coleta e análise de dados.
Aprovação por Comitê de Ética e consentimento para participação

Essa pesquisa foi aprovada pelo Comitê de Ética em Pesquisa Envolvendo Seres Humanos da Universidade Estadual de Londrina (UEL) por meio do parecer $n^{\circ} 2.219 .037$.

\section{Consentimento para publicação}

Os sujeitos da pesquisa foram informados do parecer favorável à execução emitido pelo Comitê de Ética em Pesquisa Envolvendo Seres Humanos da Universidade Estadual de Londrina (UEL), bem como tiveram acesso ao Termo de Consentimento Livre e Esclarecido (TCLE) em que é mencionado o uso dos dados para fins desta pesquisa, efetuando a assinatura deste.

\section{Conflito de interesses}

Não há conflito de interesses. 